\title{
Effect of atmospheric aging on volatility and reactive oxygen species of biodiesel exhaust nano-particles
}

\author{
A. M. Pourkhesalian ${ }^{1}$, S. Stevanovic ${ }^{1}$, M. M. Rahman ${ }^{1}$, E. M. Faghihi ${ }^{1}$, S. E. Bottle ${ }^{1}$, A. R. Masri ${ }^{2}$, R. J. Brown ${ }^{1}$, and \\ Z. D. Ristovski ${ }^{1}$ \\ ${ }^{1}$ ILAQH and BERF, Queensland University of Technology, Brisbane, QLD 4001, Australia \\ ${ }^{2}$ Clean Combustion Research Group, The University of Sydney, NSW 2006, Australia
}

Correspondence to: Z. D. Ristovski (z.ristovski@qut.edu.au)

Received: 2 February 2015 - Published in Atmos. Chem. Phys. Discuss.: 5 March 2015

Revised: 18 July 2015 - Accepted: 29 July 2015 - Published: 17 August 2015

\begin{abstract}
In the prospect of limited energy resources and climate change, effects of alternative biofuels on primary emissions are being extensively studied. Our two recent studies have shown that biodiesel fuel composition has a significant impact on primary particulate matter emissions. It was also shown that particulate matter caused by biodiesels was substantially different from the emissions due to petroleum diesel. Emissions appeared to have higher oxidative potential with the increase in oxygen content and decrease of carbon chain length and unsaturation levels of fuel molecules. Overall, both studies concluded that chemical composition of biodiesel is more important than its physical properties in controlling exhaust particle emissions. This suggests that the atmospheric aging processes, including secondary organic aerosol formation, of emissions from different fuels will be different as well. In this study, measurements were conducted on a modern common-rail diesel engine. To get more information on realistic properties of tested biodiesel particulate matter once they are released into the atmosphere, particulate matter was exposed to atmospheric oxidants, ozone and ultraviolet light; and the change in their properties was monitored for different biodiesel blends. Upon the exposure to oxidative agents, the chemical composition of the exhaust changes. It triggers the cascade of photochemical reactions resulting in the partitioning of semi-volatile compounds between the gas and particulate phase. In most of the cases, aging lead to the increase in volatility and oxidative potential, and the increment of change was mainly dependent on the chemical composition of fuels as the leading cause for the amount and the type of semi-volatile compounds present in the exhaust.
\end{abstract}

\section{Introduction}

In the urban environments the most significant contributor to the overall PM burden are traffic emissions (Pey et al., 2009). Harmful effects of DPM to humans and the environment have been extensively studied which resulted in the classification of Diesel Exhaust (DE) as carcinogenic by International Agency for Research on Cancer (IARC) (World Health Organization, 2013) in 2013. Following this, environmental agencies will tend to implement more stringent regulations to meet air quality standards forcing engine manufacturers to further reduce engine emissions. As biodiesel produces significantly less particulate matter (Surawski et al., 2013; Fontaras et al., 2009; Rahman et al., 2014) along with other economical and environmental advantages (Tinsdale et al., 2010; Kalligeros et al., 2003; Cheng et al., 2008); it may be the available option of the fuel industry in reducing PM emissions.

Numerous studies reported the decrease in some controlled emissions with the usage of biodiesel (Bagley et al., 1998; Kalligeros et al., 2003; Knothe et al., 2006; Surawski et al., 2013; Rahman et al., 2014). It is also well established that biodiesel decreases black carbon emissions and increases the Soluble Organic Fraction (SOF) (Rahman et al., 2014; Sidhu et al., 2001). The decrease in particle emissions is also very often followed by the emission of smaller particles (Surawski et al., 2013), while the increase in SOF results in excessive amount of volatile and semi-volatile matter in the exhaust (Sidhu et al., 2001; Liu et al., 2008; Surawski et al., 2011). Both the decrease in particle size and the increase in SOF are 
believed to be linked to the increase of Oxidative Potential (OP) of particles (Biswas et al., 2009; Surawski et al., 2011).

People in urban and semi-urban environments are mainly exposed to a combination of fresh and aged primary emissions and SOA. The generation of SOA occurs during aging of primary emissions, mainly through oxidation of gas-phase organic compounds that can result either in the formation of new particles or condensation of these compounds onto preexisting particles (Zielinska, 2005; Jathar et al., 2013). Consequently, atmospheric fate or aging of diesel exhaust has become of a great scientific interest and attracts significant attention from the researchers (Chirico et al., 2010; Leskinen et al., 2007; Miracolo et al., 2010, 2011; Nakao et al., 2011; Samy and Zielinska, 2010; Verma et al., 2009; Wang et al., 2011; Weitkamp et al., 2007). Although there are several studies on the aging of diesel exhaust, (Geiger et al., 2002; Lee et al., 2004; Leskinen et al., 2007; Robinson et al., 2007; Weitkamp et al., 2007; Li et al., 2009; Chirico et al., 2010; Miracolo et al., 2010; Nakao et al., 2011; Jathar et al., 2013), still a number of questions remained unanswered. Given the fact that biodiesel produces more of semi-volatile matter and thus the contribution of biodiesels to SOA formation in urban environments could be significant, the atmospheric aging of biodiesel exhaust is yet to be explored in more detail.

Smog chambers are extensively used to conduct aging experiments on anthropogenic aerosols and investigate their potential to form SOA (Izumi and Fukuyama, 1990; Atkinson et al., 1980; Sidhu et al., 2001). Recently, flow-through reactors are drawing a great deal of attention for their advantages over smog chambers. While the use of smog-chambers to study the photochemical aging processes (Chirico et al., 2010; Leskinen et al., 2007; Miracolo et al., 2010, 2011; Nakao et al., 2011; Samy and Zielinska, 2010; Verma et al., 2009; Wang et al., 2011; Weitkamp et al., 2007) has been shown to be a valuable tool, there are some significant disadvantages associated with their usage. Their size, complexity, high cost and operational time required (typically only one experiment per day) make them impractical when series of experiments need to be conducted. As an alternative to smog chambers, flowthrough reactors or "Potential Aerosol Mass" (PAM) chambers are becoming very popular among researchers (Kang et al., 2007; Lambe et al., 2011; Keller and Burtscher, 2012). PAM chambers simulate atmospheric photo oxidation processes. Employment of PAM chambers is associated with high oxidant concentrations and short exposure times mimicking few hours to few days of real-time atmospheric oxidation. The short residence time of PAM chambers further enables better control of the oxidant concentrations and minimizes wall losses, which could be significant in smog chambers (Kang et al., 2007). Also the response time in PAM chambers is by far less than that of smog chambers making it easier to observe the effect of changing a control variable. Moreover, experiments carried out on PAM chambers tend to be more repeatable and more reproducible (Kang et al., 2007).
So far, the PAM chambers have been used to investigate the potential of combustion generated aerosols to produce SOA including biomass burning (Keller and Burtscher, 2012) and two-stroke engine exhaust (McWhinney et al., 2011). The potential of biodiesel exhaust gases to cause SOA formation is yet to be studied.

This research investigates the change in volatile organic content and the potential toxicity of biodiesel exhaust particulate matter after aging in a flow-through reactor. We explore the contribution of photochemical aging processes on the potential transfer of the semi-volatile fraction of biodiesel exhaust from the gas phase to the particle phase and the extent to which semi-volatile compounds are related to chemically active molecules that contain oxygen or Reactive Oxygen Species (ROS). The study also aims to find a correlation between the chemical composition of biodiesel and the volatility and toxicity of biodiesel particulate matter while undergoing simulated aging processes. Specifically the main objective of this work is to critically examine the influence of the carbon chain length, saturation levels and oxygen content of biodiesel Fatty Acid Methyl Ester (FAME) fuel molecules. All the work has been undertaken by investigating particle emissions from a common-rail engine using four palm oil biodiesels at different blend percentages.

\section{Experimental setup and methodology}

Figure 1 illustrates the experimental setup. The setup was composed of an existing EURO III diesel engine which was mounted on an engine dynamometer within the Biofuels Engine Research Facility (BERF) at Queensland University of Technology (QUT), and was used as the test bed. The engine was a six-cylinder, turbo-charged, common-rail, Euro III, compression ignition engine with the displacement volume of 5.9 L. More details of the experimental setup, engine specifications, dilution system along with the chemical and physical properties of fuels used can be found in our previous publication (Rahman et al., 2014). The main addition was that the diluted exhaust was passed through a flow-through reactor (PAM reactor) where the diluted exhaust is mixed with ozone and irradiated with UV light.

The flow-through-reactor was a 1-m-long stainless steel cylinder which had four inlet ports and four outlet ports. There were also four lengthwise sampling points to enable measurement along the reactor length. In the center of the reactor, there was space for a UV tube to irradiate the diesel exhaust. Considering the dimensions of the reactor, the UV tube as well as the flow rate through the reactor $\left(7 \pm 0.5 \mathrm{~L} \mathrm{~min}^{-1}\right)$, the residence time (treatment time) of the reactor was estimated to be $60 \pm 10 \mathrm{~s}$. The amount of time the exhaust gas was exposed to simulated atmospheric conditions was much less than in the real conditions therefore the concentration of ozone and exposure to UV had to be higher compared to real atmospheric conditions. Based on a previous literature, this 


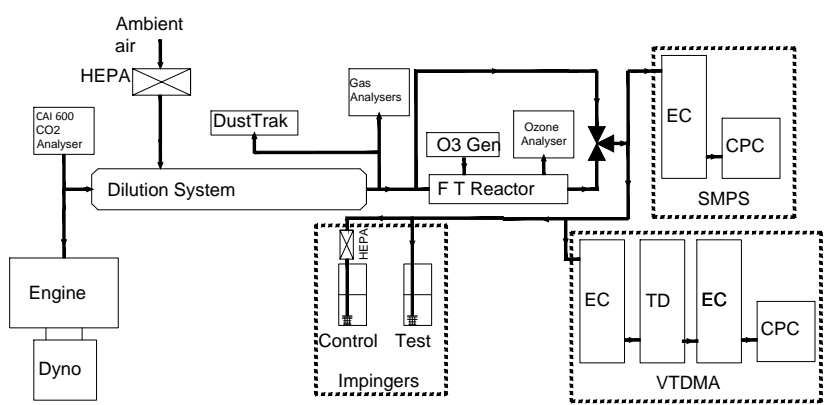

Figure 1. Experiment setup HEPA: High-Efficiency Particulate Air Filter; F T reactor: Flow-Trough Reactor; O3 Gen: Ozone Generator; Ozone Analyser: EC9810 Ecotech; EC: Electrostatic Classifier; TD: Thermo-Denuder; VTDMA: Volatility Tandem Differential Mobility Analyser; CPC: Condensation Particle Counter; SMPS: Scanning Mobility Particle Sizer; Impingers: used to collect DPM for ROS measurements.

residence time approximately correlated to an exposure of at least 2 to $8 \mathrm{~h}$ in the atmosphere (McWhinney et al., 2011). After aging in the reactor, diesel exhaust went to a number of different devices capable of measuring a variety of physical and chemical properties of gases and particles which will be explained later.

Purified air was drawn through the ozone generator (Ozonizer HLO 800) and was injected into the reactor where it was mixed with diluted and cooled diesel exhaust. The flow rate through the ozone generator was restricted using a critical orifice and was measured to be $0.15 \mathrm{~L} \mathrm{~min}^{-1}$. To continuously monitor the concentration of ozone in the reactor an Echotech EC9810 Ozone Analyser was used. The average concentration of ozone in the reactor was kept to be around $0.5 \pm 0.1 \mathrm{ppm}$ during aging experiments. OH radical formation was not monitored and reported as this was a qualitative study showing the general effect without the quantification of SOA yields.

As mentioned before, to simulate sunlight and reactions induced by the irradiation of UV from the sun (Kang et al., 2007; Keller and Burtscher, 2012), there was a space for a UV tube in the center of the reactor which was suitable to fit different types of UV light tubes (UV-A, UV-B and UV-C). The UV tube which was used in this study mostly emitted UV light at $253 \mathrm{~nm}$ wave length (UVC).

A standard set of gas analyser was used to continuously monitor the concentrations of $\mathrm{CO}, \mathrm{CO}_{2}$ and $\mathrm{NO}_{x}$. More details on the gas analyser set is described in a recent publication (Rahman et al., 2014).

Using a TSI Dustrak (model 8530) and applying the procedure proposed by Jamriska (Jamriska et al., 2004) the mass concentration of particles was estimated and was used to normalize the ROS levels of the diesel exhaust. A Scanning Mobility Particle Sizer (SMPS TSI 3080, with a 3022 CPC) measured the size distribution of diesel exhaust. A Volatility Tandem Differential Mobility Analyser (VTDMA) con- sisting of an electrostatic classifier, a thermo-denuder and an SMPS (in-house designed column with a 3010 CPC) measured the amount of volatile matter in the diesel exhaust particles (Johnson et al., 2008). The VTDMA yielded the change in the diameter of particles for six pre-selected sizes: 30,60 , $90,120,150,200$ and $220 \mathrm{~nm}$ after they have passed through the thermo-denuder with the temperature set at $30{ }^{\circ} \mathrm{C}$. Using the VTDMA method, the volatility of particles was compared before and after aging in the reactor. The error range for the particle sizing instruments was less than 1 percent that led to a maximum $3 \%$ error for the volatility measurements (Pourkhesalian et al., 2014).

To measure the ROS levels of diesel exhaust of different fuel stocks before and after aging, the BPEA molecular probe (bis(phenylethynyl) anthracene-nitroxide) was applied in situ. Samples were collected by bubbling aerosol through an impinger containing $20 \mathrm{~mL}$ of $4 \mu \mathrm{M}$ BPEA solution which used an AR grade dimethylsulphoxide as the solvent. More details on the ROS sampling methodology, theory behind its application and proof of concept in the case of various combustion sources can be found in previous publications (Miljevic et al., 2009, 2010; Stevanovic et al., 2012a, b, 2013).

\subsection{Fuel selection}

In this study four FAME fuels with controlled chemical compositions were tested and compared to petro-diesel. The fuels differed in terms of iodine value and saponification value which correspond to saturation degree and oxygen content of the fuels respectively. To differentiate the effects caused by change of saturation degree from those caused by oxygen content, two of the biodiesels had very close saturation levels but different carbon chain lengths, while the other two biodiesels were the same in terms of oxygen content but different in saturation levels. We used commercial petro-diesel to make 20 and $50 \%$ biodiesel blends. The FAMEs are labeled as C810, C1214, C1618 and C1875, based on the number of carbon atoms in the most abundant fatty acid in that particular biodiesel stock. Some of the most important chemical and physical prosperities of the fuels can be found in a previous study by Rahman et al. (2014).

\subsection{Operation of the engine}

Blends of 100, 50, 20 and $0 \%$ of biodiesel, noted as B100 (pure biodiesel), B50 and B20 and B0 (pure petro-diesel) respectively, were used to run the engine. All the tests were conducted at quarter load and at the engine speed of 1500 rpm. Tests were not done at several different loads and speeds to avoid too many variables. This test was designed to isolate the influence of changing fuel composition on the aging potential and related physico-chemical changes in PM. 


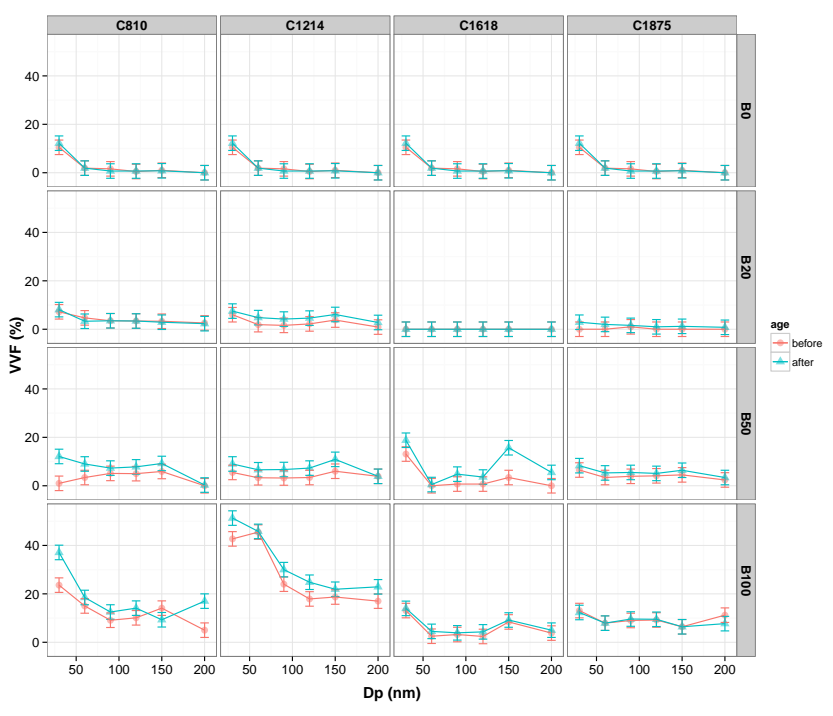

Figure 2. The volumetric volatile fraction (vvf) of particles versus particle pre-selection sizes for different biodiesels and different blends before and after aging. Each column is dedicated to one of the biodiesels and each row specifies one blend. Red markers represent the particles before aging and blue markers show the particles after aging. Error bars show the SEM for V-TDMA. All the tests were carried out at quarter load, $1500 \mathrm{rpm}$.

\section{Results and discussion}

\subsection{Volatility measurements}

Figure 2 shows the change in Volumetric Volatile Fraction (VVF) of particulate component before and after exposure to UV light and ozone. A possible increase of volatile content of the particles after the exposure to oxidative agents can be seen in the figure. As the vapor pressure of the gases reduces due to photochemical reactions, some of the volatile substances partition form the gas phase into the particle phase resulting in more volatile particles (Leskinen et al., 2007; Donahue et al., 2006; Kroll and Seinfeld, 2008). It was observed that the exposure to oxidative agents did not lead to the formation of nucleation mode particles. It is to be noted that in cases when the dilution ratio is low and there is not enough surfaces available for the partitioning gas to condense on (e.g. application of diesel particulate filters), then formation of nucleation mode particles can occur (Lipsky and Robinson, 2006), but at high levels of dilution, semi-volatile compounds tend to partition in the gas phase (Robinson et al., 2007). The reason why we did not observe any nucleation mode particles was that the dilution ratio was rather large at more than 400 and there was no diesel particulate filter in use, so there were already surfaces available for the condensation of gaseous matter (Shi and Harrison, 1999; Rönkkö et al., 2006)

In Fig. 2, it can be seen that the volatility of particles has increased with the increase of biodiesel percentage in the blends (Pourkhesalian et al., 2014). While for B20, the amount of volatile matter is quite close to that of $\mathrm{B} 0$; the volatility of particles has increased considerably with B50 and B100. These findings were in a good agreement with the previous observations, which showed a significant increase in volatility of diesel particulate matter with increasing biodiesel percentage in the blend (Pourkhesalian et al., 2014; Surawski et al., 2011). Particles produced by the combustion of $\mathrm{C} 810$ and $\mathrm{C} 1214$ were the most volatile; also the change in volatility of these particles was more significant with increasing percentage of biodiesel in the blend; whereas, the change in volatility was almost negligible for C1875 and all of its blends which was the most unsaturated biodiesel with the longest carbon chain length and lowest oxygen content.

The effect of oxygen content on the volatility of particles with gaseous and liquid diesel fuels was studied previously (Sidhu et al., 2001; Xu et al., 2013; Pourkhesalian et al., 2014) and in our study, the increase of volatile matter in particles is more significant for more saturated fuels and with more oxygen content; where for $\mathrm{C} 1875$ the increase is just within the error range of the instrument.

The volatile fraction and the growth of volatile fraction for $30 \mathrm{~nm}$ particles were the largest in almost all cases which showed that more attention is to be paid to smaller particles; not only because of their ability to suspend longer and penetrate deeper in the lung (Sidhu et al., 2001; Liu et al., 2008; Surawski et al., 2011; Cheung et al., 2009), but also because of their probability of carrying more oxidized volatile organics as they age.

In B0, apart from $30 \mathrm{~nm}$ particles, for all other particle sizes, the amount of volatile matter is within the error range of the differential mobility analyzer (DMA), implying that B0 emits particles that are mainly composed of soot. Also after aging experiments, the increase in volatile fraction in B0 particles was just small enough to be neglected showing that either the amount of volatile matter in the gas phase is very small or they do not undergo photochemical reactions.

To be able to compare cases more easily, we have estimated the total amount of volatile matter that is in the liquid phase for each case and we called it Overall Volatility (OV). To do so, particles are assumed to be spherical. The volume of volatile matter is estimated using VTDMA data and the number concentration of each pre-selection size from SMPS data. The quantity, OV, is expressed through percentage and means that a certain proportion of the PM in the aerosol is composed of volatile matter while the rest is non-volatile (mainly elemental carbon) (Giechaskiel et al., 2009). More details of the concept and the procedure of estimating OV can be found in our recent study (Pourkhesalian et al., 2014).

Figure 3 illustrates the $\mathrm{OV}$ of diesel exhaust versus blend for different biodiesel and compared to petro-diesel. As previously observed (Surawski et al., 2011), the volatility of diesel particulate matter increases as the percentage of biodiesel goes higher in the blends. This fact is particularly 


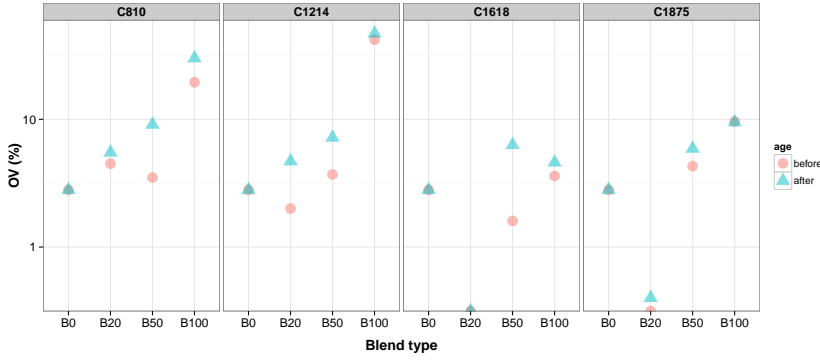

Figure 3. Volatility of particulate matter versus different blends for petro-diesel and tested biodiesels before and after aging in the flow through reactor. Blue points are due to aged particulate matter and red points represent fresh particles. Different tested biodiesels can be seen at the top of the figure. B0 representing petro-diesel is repeated in all graphs for comparison.

seen in more saturated fuels with higher oxygen content. Blends of C810 and C1214, which have short carbon chain lengths and high saturation degree, have produced emissions with the most volatile PM; while C1618 and C1875, with longer carbon chain lengths and more carbon double bonds (more saturated fuels), have produced less and less volatile PM. This can be explained by assuming that the oxygen borne with the molecule of the fuel can cause more oxidized combustion products being of low volatility both in the liquid phase and in the gas phase. Those volatile substances having a lower vapor pressure would condense on soot particles just after the combustion while in the combustion chamber or in the exhaust system, causing the volatile fraction of particle to become more significant. The volatile fraction of particles produced by more oxygenated fuels increases more after aging because there are more semi-volatile and volatile matter in the gas phase undergoing photo chemical reactions and transforming into the particle phase and condensing onto the primary particles.

The two heavier biodiesel fuels which were tested in the study (C1618 and C1875) are more unsaturated, less oxygenated and have a longer carbon chain length and thus are more comparable to petro-diesel. Both of them caused more volatile PM compared to B0 and their increase in volatility was not as significant as the two other biodiesel fuels in this study.

PM due to short-length hydrocarbons blends (C810 and C1214) was more volatile before, but also after the aging process. It can be seen that the carbon chain length of the fuel was a more influential factor on the volatility of PM than saturation degree of the fuel. The reason would be the fact that when the carbon chain length is shorter, the weight ratio of oxygen borne by the fuel molecule will be higher and thus more oxidative agent is available for the organics, so the vapor pressure of the products, whether before or after the exposure, will be further lowered as a result of oxidization. To examine this supposition, the oxygen content of all the fuels and blends were either measured or calculated,

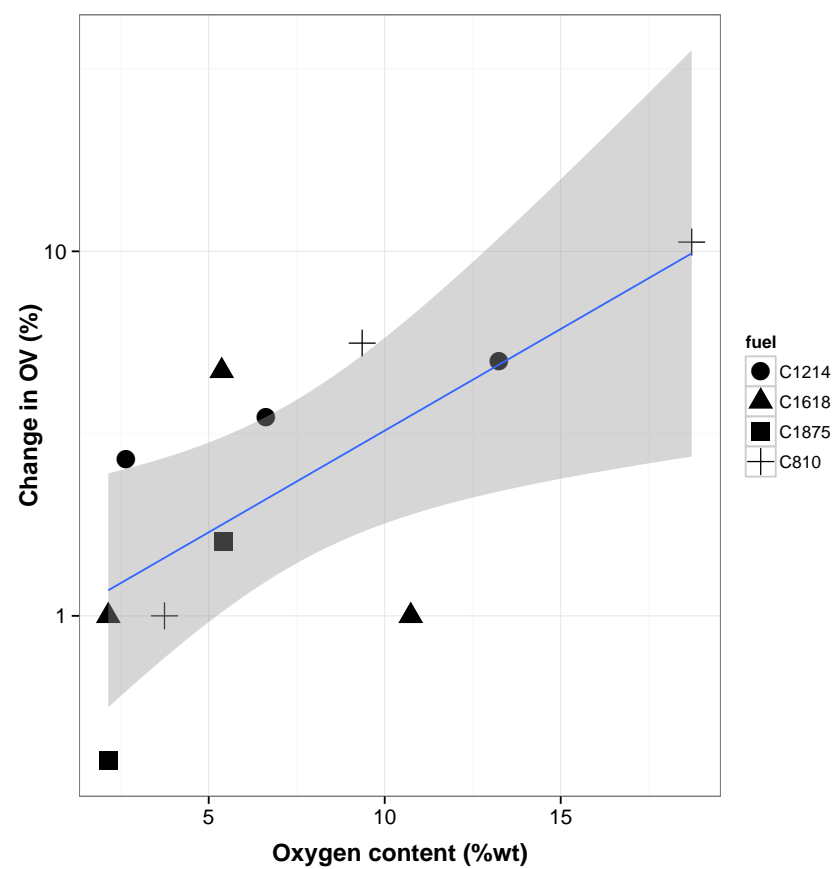

Figure 4. Change in volatility of particles before and after aging against oxygen content of the blends. Different fuels are shown with different shapes as can be seen in the legend. The point corresponding to $\mathrm{C} 1875$, B100 is excluded from the model. The grey area shows the $95 \%$ confidence interval of the fit. $R^{2}=0.66$.

and then the change in the volatility of PM emitted by each blend (after aging) was plotted against the oxygen content of the blends (Fig. 4). The effect of oxygen content of the blend on the increase of the volatile matter in the DPM is evident. Apart from two points (C1618, B100 and C1875, B100) that show low volatility with higher oxygen content; all other blends showed a good correlation between volatility and oxygen content.

The correlations between the variables were analyzed using the linear regression or generalized linear model with a $\log$ link function. The validation of model assumptions was performed by the residuals versus fit values and $Q-Q$ plots. Modeling and visualizations were carried out using the ggplot2 package in $\mathrm{R}$ (Wickham, 2009).

\subsection{ROS measurements}

Oxidative potential measurement, expressed through ROS concentration of PM can be used as a good estimate for its reactivity and toxicity. An in-house developed profluorescent molecular probe BPEAnit was applied in an entirely novel, rapid and non-cell based way to assess particulate oxidative potential. Based on the data provided in the literature so far (Stevanovic et al., 2013), there are some uncertainties related to the nature of chemical species responsible for the measured redox potential and overall toxicity. However, the majority of research in this field reported that organic 


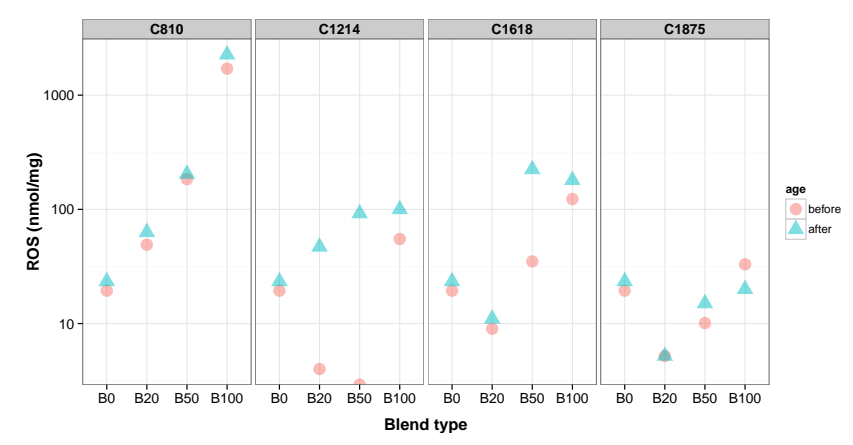

Figure 5. ROS levels of particulate matter versus different blends for petro-diesel and tested biodiesels before aging (red circles) and after aging (blue triangles). Different tested biodiesels can be seen at the top of the figure. B0 representing petro-diesel is repeated in all graphs for comparison.

fraction, more precisely semi-volatile organic content, is in a good correlation with ROS concentration (Biswas et al., 2009; Miljevic et al., 2010; Surawski et al., 2011).

Figure 5 illustrates the oxidative potential of particles for all three biodiesel blends at $25 \%$ load, $1500 \mathrm{rpm}$ before and after the aging process. The points corresponding to $\mathrm{B} 0$ are repeatedly presented in all blends to ease comparison of petro-diesel particulate oxidative potential with that of other blends. It is evident that the aging process increases potential toxicity of particles by increasing ROS concentration in the case of all four biodiesel as well as petro-diesel. This result is supported by volatility measurements. As stated above, particles become more volatile after aging as a result of oxidation of semi-volatile compounds and their subsequent condensation onto pre-existing particles.

In Fig. 5, the change in ROS content after exposure to UV and ozone is the most significant in the case of B100, and this increase in oxidative potential decreases with the decreasing percentage of biodiesels in blends. To further explore this, the change in ROS concentration was plotted against oxygen content of the fuels. A possible trend between the fuel oxygen content and ROS concentration is evident from Fig. 6. The actual mechanism standing behind this aging transformation and subsequent partitioning remains unclear and is subject to further investigation. However, this graph is showing an indication that the amount of increased ROS concentration upon oxidative aging is more significant in the case of PM originating from the combustion of molecules with higher oxygen content. To get a further insight into the aging process of tested aerosols, the oxidative potential of the gas phase was measured as well. The results are summarised in Fig. 7 and they show interesting trends. When the compounds from the gas phase are oxidized they are transferred into the particle phase due to the decrease of their saturation vapor pressure. In this case one would expect a decrease in the concentration of the gaseous component after aging. This is the case with long chain, unsaturated biodiesels-C1875,

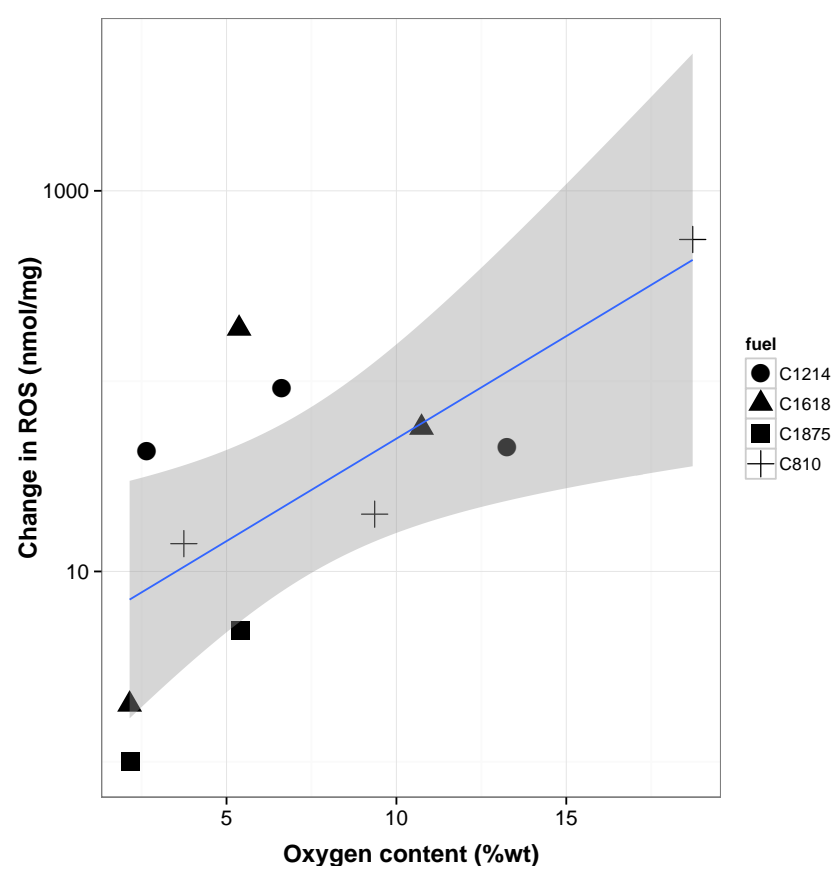

Figure 6. The correlation between the change in ROS levels and oxygen content the fuels before and after aging. The point corresponding to $\mathrm{C} 1875$ is excluded from the model. The grey area shows the $95 \%$ confidence interval of the fit. $R^{2}=0.52$.

C1618 and to some extent to C1214, as well as with petrodiesel that generally consists of around $75 \%$ of paraffins and $\sim 25 \%$ of unsaturated compounds (In the literature the average formula for diesel is $\mathrm{C} 12 \mathrm{H} 23$ (Heywood, 1988), corresponding to C12 fuel but with no oxygen).

On the contrary fuels with higher oxygen content show an increase in the oxidative potential of the gas phase. This could be due to the vapor pressure of the oxidized gas phase compounds not being low enough to lead to the condensation onto the particle phase. By looking at the volatility change in respect to aging, it is obvious that the volatility increases upon exposure to UV and ozone for all the fuels. This may mean that in the case of short-chain, saturated biodiesels, aging leads to the condensation of certain species from the gas phase, which further increases OV, but does not carry any ROS potency.

The correlation between overall volatility of diesel particulate matter and the ROS can be seen in Fig. 8. This figure shows the measured ROS levels and volatility of particulate matter for all the modes and blends both before and after aging. Blue markers are due to fresh particles and red markers are due to aged particulate matter. Particulate matter produced by each fuel is specified using a symbol as can be seen in the legends. This categorization method allows us to easily spot clusters of a color or a symbol. The first observation from Fig. 8 is that the ROS correlates with OV. Note that the correlation is not linear but it is exponential. So a small increase in volatility of particulate matter can cause a sig- 


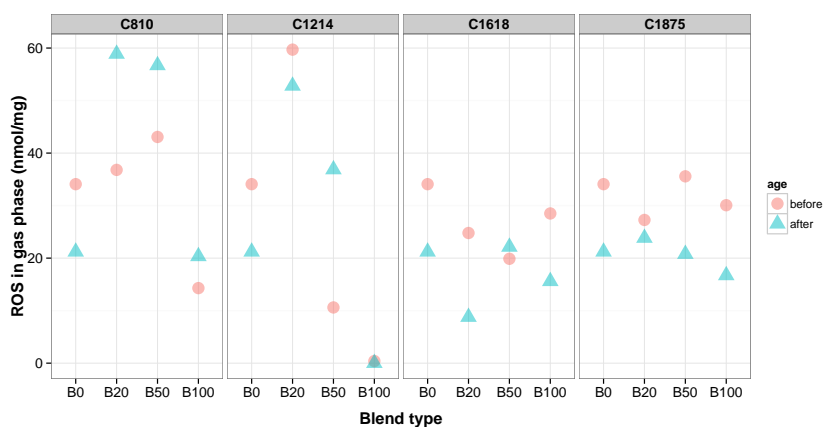

Figure 7. ROS levels in gas phase before and after aging. Fresh and aged particulate matter are separated using blue color for aged PM and red for fresh PM.

nificant increase in ROS levels. The symbols square and triangle are seen towards the right and upper side of the figure, which again shows that more saturated fuels with shorter carbon chain length can cause more volatile and particles with a higher oxidative potential. It is also evident that blue markers tend to move toward the right and upper side of the figure underlining the exacerbating effect of atmospheric aging on the biodiesel particulate matter.

\section{Conclusion}

The objective of this research was to shed some light on the potential of biodiesel exhaust to generate SOA and to compare the potential toxicity of aged particles caused by biodiesel with that of petro-diesel. The results presented here showed that chemical composition of the fuel can affect the primary emissions as well as secondary emissions. Saturated fuels causing less PM also caused more volatile PM and significantly more semi volatiles in the gas phase with the potential to partition between the gas phase and particle phase upon aging. Moreover, aged particles from more saturated fuels with higher oxygen content have a higher oxidative potential as expressed through the increase of ROS concentration. Results of this research are in contrast with a few previous studies where it was claimed that use of biodiesel did not tend to increase the level of toxicity of diesel exhaust (Bagley et al., 1998; Jung et al., 2006; Jalava et al., 2012).

This study is not quantitative and cannot be used for SOA prediction within models. However, its qualitative analysis calls for the attention of regulating authorities and contributes to the overall body of knowledge on the effects of fuel composition on both engine primary as well as secondary emissions. Once emitted to the atmosphere, PM originating from combusted biodiesel will transform and become more toxic than its parent molecules and its overall toxicity will mainly depend on the chemical properties of the fuel. Therefore categorizing all biodiesel fuels in one group, as it is in current regulations, may not be the most appropriate way of classification in respect to their emissions. Vari-

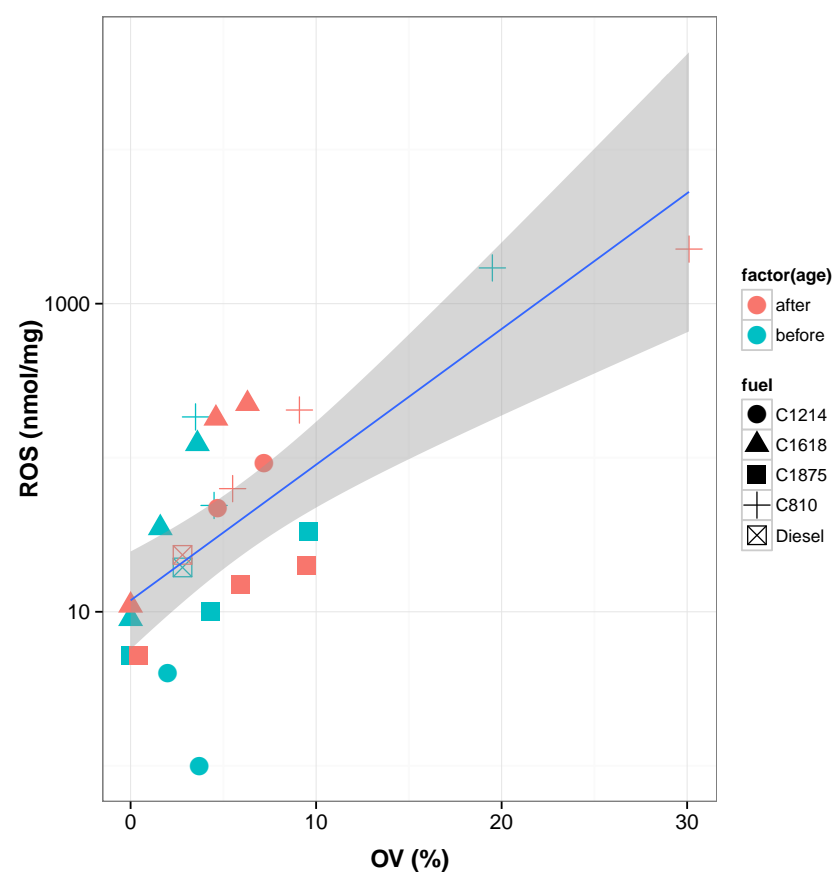

Figure 8. The correlation between ROS of particulate matter and the volatility of particulate matter. Fresh and aged particulate matter are separated using blue color for fresh PM and red for aged PM, also the shape of the markers represents different fuel. The grey area shows the $95 \%$ confidence interval of the fit. $R^{2}=0.86$.

ous biodiesel fuels are very different in terms of both physical properties and chemical compositions which combust differently causing substantially diverse species in the exhaust gases, particularly in PM and the semi-volatile fraction. Moreover, the exhaust gases from various biodiesel fuels behave differently when reacting with oxidative agents from the atmosphere. Perhaps new regulation should take some of the most important characteristics of the biodiesel into account and classify them in groups based on the oxygen content or level of saturation etc. Furthermore, current legislations only regulate the nonvolatile fraction of primary particles. There are no regulations for VOCs, semi-volatile matter and the capability of the emissions to form SOA (Giechaskiel et al., 2012). This study points out the necessity of redefining the legislations; and as experiments with flow-through reactors are more reproducible and less costly, they could be used for introduction of more stringent regulations.

Acknowledgements. The authors would like to acknowledge the support from the Australian Research Council under Grants LP110200158, DP1097125, DP130104904, DP110105535 and DP120100126. Laboratory assistance from Mr Noel Hartnett and Mr Scott Abbett were also appreciated.

Edited by: H. Saathoff 


\section{References}

Atkinson, R., Carter, W. P. L., Darnall, K. R., Winer, A. M., and Pitts, J. N.: A smog chamber and modeling study of the gas-phase nox-air photo-oxidation of toluene and the cresols, Int. J. Chem. Kinet., 12, 779-836, doi:10.1002/kin.550121102, 1980.

Bagley, S. T., Gratz, L. D., Johnson, J. H., and McDonald, J. F.: Effects of an oxidation catalytic converter and a biodiesel fuel on the chemical, mutagenic, and particle size characteristics of emissions from a diesel engine, Environ. Sci. Technol., 32, 1183 1191, doi:10.1021/es970224q, 1998.

Biswas, S., Verma, V., Schauer, J. J., Cassee, F. R., Cho, A. K., and Sioutas, C.: Oxidative potential of semi-volatile and non volatile particulate matter ( $\mathrm{pm}$ ) from heavy-duty vehicles retrofitted with emission control technologies, Environ. Sci. Technol., 43, 39053912, doi:10.1021/es9000592, 2009.

Cheng, C. H., Cheung, C. S., Chan, T. L., Lee, S. C., and Yao, C. D.: Experimental investigation on the performance, gaseous and particulate emissions of a methanol fumigated diesel engine, Sci. Total Environ., 389, 115-124, doi:10.1016/j.scitotenv.2007.08.041, 2008.

Cheung, K. L., Polidori, A., Ntziachristos, L., Tzamkiozis, T., Samaras, Z., Cassee, F. R., Gerlofs, M., and Sioutas, C.: Chemical characteristics and oxidative potential of particulate matter emissions from gasoline, diesel, and biodiesel cars, Environ. Sci. Technol., 43, 6334-6340, doi:10.1021/es900819t, 2009.

Chirico, R., DeCarlo, P. F., Heringa, M. F., Tritscher, T., Richter, R., Prévôt, A. S. H., Dommen, J., Weingartner, E., Wehrle, G., Gysel, M., Laborde, M., and Baltensperger, U.: Impact of aftertreatment devices on primary emissions and secondary organic aerosol formation potential from in-use diesel vehicles: results from smog chamber experiments, Atmos. Chem. Phys., 10, 11545-11563, doi:10.5194/acp-10-11545-2010, 2010.

Donahue, N. M., Robinson, A. L., Stanier, C. O., and Pandis, S. N.: Coupled partitioning, dilution, and chemical aging of semivolatile organics, Environ. Sci. Technol., 40, 2635-2643, doi:10.1021/es052297c, 2006.

Fontaras, G., Karavalakis, G., Kousoulidou, M., Tzamkiozis, T., Ntziachristos, L., Bakeas, E., Stournas, S., and Samaras, Z.: Effects of biodiesel on passenger car fuel consumption, regulated and non-regulated pollutant emissions over legislated and real-world driving cycles, Fuel, 88, 1608-1617, doi:10.1016/j.fuel.2009.02.011, 2009.

Geiger, H., Kleffmann, J., and Wiesen, P.: Smog chamber studies on the influence of diesel exhaust on photosmog formation, Atmos. Environ., 36, 1737-1747, doi:10.1016/s1352-2310(02)00175-9, 2002.

Giechaskiel, B., Alfoldy, B., and Drossinos, Y.: A metric for health effects studies of diesel exhaust particles, J. Aerosol Sci., 40, 639-651, doi:10.1016/j.jaerosci.2009.04.008, 2009.

Giechaskiel, B., Mamakos, A., Andersson, J., Dilara, P., Martini, G., Schindler, W., and Bergmann, A.: Measurement of automotive nonvolatile particle number emissions within the european legislative framework: A review, Aerosol Sci. Technol., 46, 719749,2012

Heywood, J. B.: Internal combustion engine fundamentals, Mcgraw-hill New York, 1988.

Izumi, K. and Fukuyama, T.: Photochemical aerosol formation from aromatic-hydrocarbons in the presence of nox, At- mos. Environm. A-Gen., 24, 1433-1441, doi:10.1016/09601686(90)90052-o, 1990.

Jalava, P. I., Aakko-Saksa, P., Murtonen, T., Happo, M. S., Markkanen, A., Yli-Pirilä, P., Hakulinen, P., Hillamo, R., MäkiPaakkanen, J., and Salonen, R. O.: Toxicological properties of emission particles from heavy duty engines powered by conventional and bio-based diesel fuels and compressed natural gas, Particle and fibre toxicology, 9, 37, doi:10.1186/1743-8977-937, 2012.

Jamriska, M., Morawska, L., Thomas, S., and He, C.: Diesel bus emissions measured in a tunnel study, Environ. Sci. Technol., 38, 6701-6709, 2004.

Jathar, S. H., Miracolo, M. A., Tkacik, D. S., Donahue, N. M., Adams, P. J., and Robinson, A. L.: Secondary organic aerosol formation from photo-oxidation of unburned fuel: Experimental results and implications for aerosol formation from combustion emissions, Environ. Sci. Technol., 47, 12886-12893, doi:10.1021/es403445q, 2013.

Johnson, G. R., Fletcher, C., Meyer, N., Modini, R., and Ristovski, Z.: A robust, portable h-tdma for field use, J. Aerosol Sci., 39, 850-861, 2008.

Jung, H., Kittelson, D. B., and Zachariah, M. R.: Characteristics of sme biodiesel-fueled diesel particle emissions and the kinetics of oxidation, Environ. Sci. Technol., 40, 4949-4955, doi:10.1021/es0515452, 2006.

Kalligeros, S., Zannikos, F., Stournas, S., Lois, E., Anastopoulos, G., Teas, C., and Sakellaropoulos, F.: An investigation of using biodiesel/marine diesel blends on the performance of a stationary diesel engine, Biomass Bioenerg., 24, 141-149, 2003.

Kang, E., Root, M. J., Toohey, D. W., and Brune, W. H.: Introducing the concept of Potential Aerosol Mass (PAM), Atmos. Chem. Phys., 7, 5727-5744, doi:10.5194/acp-7-5727-2007, 2007.

Keller, A. and Burtscher, H.: A continuous photo-oxidation flow reactor for a defined measurement of the soa formation potential of wood burning emissions, J. Aerosol Sci., 49, 9-20, doi:10.1016/j.jaerosci.2012.02.007, 2012.

Knothe, G., Sharp, C. A., and Ryan III, T. W.: Exhaust emissions of biodiesel, petrodiesel, neat methyl esters, and alkanes in a new technology engine, Energy Fuels, 20, 403-408, 2006.

Kroll, J. H. and Seinfeld, J. H.: Chemistry of secondary organic aerosol: Formation and evolution of low-volatility organics in the atmosphere, Atmos. Environ., 42, 3593-3624, doi:10.1016/j.atmosenv.2008.01.003, 2008.

Lambe, A. T., Ahern, A. T., Williams, L. R., Slowik, J. G., Wong, J. P. S., Abbatt, J. P. D., Brune, W. H., Ng, N. L., Wright, J. P., Croasdale, D. R., Worsnop, D. R., Davidovits, P., and Onasch, T. B.: Characterization of aerosol photooxidation flow reactors: heterogeneous oxidation, secondary organic aerosol formation and cloud condensation nuclei activity measurements, Atmos. Meas. Tech., 4, 445-461, doi:10.5194/amt-4-445-2011, 2011.

Lee, S., Jang, M., and Kamens, R. M.: Soa formation from the photooxidation of $\alpha$-pinene in the presence of freshly emitted diesel soot exhaust, Atmos. Environ., 38, 2597-2605, doi:10.1016/j.atmosenv.2003.12.041, 2004.

Leskinen, A. P., Jokinlemi, J. K., and Lehtinen, K. E. J.: Transformation of diesel engine exhaust in an environmental chamber, Atmos. Environ., 41, 8865-8873, doi:10.1016/j.atmosenv.2007.08.021, 2007. 
Li, Q., Wyatt, A., and Kamens, R. M.: Oxidant generation and toxicity enhancement of aged-diesel exhaust, Atmos. Environ., 43, 1037-1042, doi:10.1016/j.atmosenv.2008.11.018, 2009.

Lipsky, E. M. and Robinson, A. L.: Effects of dilution on fine particle mass and partitioning of semivolatile organics in diesel exhaust and wood smoke, Environ. Sci. Technol., 40, 155-162, doi:10.1021/es050319p, 2006.

Liu, Y. Y., Lin, T. C., Wang, Y. J., and Ho, W. L.: Biological toxicities of emissions from an unmodified engine fueled with diesel and biodiesel blend, J. Environ. Sci. Heal. A, 43, 1735-1743, doi:10.1080/10934520802330438, 2008.

McWhinney, R. D., Gao, S. S., Zhou, S. M., and Abbatt, J. P. D.: Evaluation of the effects of ozone oxidation on redox-cycling activity of two-stroke engine exhaust particles, Environ. Sci. Technol., 45, 2131-2136, doi:10.1021/es102874d, 2011.

Miljevic, B., Modini, R. L., Bottle, S. E., and Ristovski, Z. D.: On the efficiency of impingers with fritted nozzle tip for collection of ultrafine particles, Atmos. Environ., 43, 1372-1376, doi:10.1016/j.atmosenv.2008.12.001, 2009.

Miljevic, B., Heringa, M. F., Keller, A., Meyer, N. K., Good, J., Lauber, A., Decarlo, P. F., Fairfull-Smith, K. E., Nussbaumer, T., Burtscher, H., Prevot, A. S. H., Baltensperger, U., Bottle, S. E., and Ristovski, Z. D.: Oxidative potential of logwood and pellet burning particles assessed by a novel profluorescent nitroxide probe, Environ. Sci. Technol., 44, 6601-6607, doi:10.1021/es100963y, 2010.

Miracolo, M. A., Presto, A. A., Lambe, A. T., Hennigan, C. J., Donahue, N. M., Kroll, J. H., Worsnop, D. R., and Robinson, A. L.: Photo-oxidation of low-volatility organics found in motor vehicle emissions: Production and chemical evolution of organic aerosol mass, Environ. Sci. Technol., 44, 1638-1643, doi:10.1021/es902635c, 2010.

Miracolo, M. A., Hennigan, C. J., Ranjan, M., Nguyen, N. T., Gordon, T. D., Lipsky, E. M., Presto, A. A., Donahue, N. M., and Robinson, A. L.: Secondary aerosol formation from photochemical aging of aircraft exhaust in a smog chamber, Atmos. Chem. Phys., 11, 4135-4147, doi:10.5194/acp-11-4135-2011, 2011.

Nakao, S., Shrivastava, M., Nguyen, A., Jung, H. J., and Cocker, D.: Interpretation of secondary organic aerosol formation from diesel exhaust photooxidation in an environmental chamber, Aerosol Sci. Technol., 45, 964-974, doi:10.1080/02786826.2011.573510, 2011.

Pey, J., Querol, X., Alastuey, A., Rodríguez, S., Putaud, J. P., and Van Dingenen, R.: Source apportionment of urban fine and ultrafine particle number concentration in a western mediterranean city, Atmos. Environ., 43, 4407-4415, 2009.

Pourkhesalian, A. M., Stevanovic, S., Salimi, F., Rahman, M., Wang, H., Pham, P. X., Bottle, S. E., Masri, A., Brown, R. J., and Ristovski, Z. D.: Influence of fuel molecular structure on the volatility and oxidative potential of biodiesel particulate matter, Environ. Sci. Technol., 48, 12577-12585, 2014.

Rahman, M. M., Pourkhesalian, A. M., Jahirul, M. I., Stevanovic, S., Pham, P. X., Wang, H., Masri, A. R., Brown, R. J., and Ristovski, Z. D.: Particle emissions from biodiesels with different physical properties and chemical composition, Fuel, 134, 201208, doi:10.1016/j.fuel.2014.05.053, 2014.

Robinson, A. L., Donahue, N. M., Shrivastava, M. K., Weitkamp, E. A., Sage, A. M., Grieshop, A. P., Lane, T. E., Pierce, J. R., and Pandis, S. N.: Rethinking organic aerosols: Semivolatile emissions and photochemical aging, Science, 315, 1259-1262, doi:10.1126/science.1133061, 2007.

Rönkkö, T., Virtanen, A., Vaaraslahti, K., Keskinen, J., Pirjola, L., and Lappi, M.: Effect of dilution conditions and driving parameters on nucleation mode particles in diesel exhaust: Laboratory and on-road study, Atmos. Environ., 40, 2893-2901, doi:10.1016/j.atmosenv.2006.01.002, 2006.

Samy, S. and Zielinska, B.: Secondary organic aerosol production from modern diesel engine emissions, Atmos. Chem. Phys., 10, 609-625, doi:10.5194/acp-10-609-2010, 2010.

Shi, J. P. and Harrison, R. M.: Investigation of ultrafine particle formation during diesel exhaust dilution, Environ. Sci. Technol., 33 3730-3736, doi:10.1021/es9811871, 1999.

Sidhu, S., Graham, J., and Striebich, R.: Semi-volatile and particulate emissions from the combustion of alternative diesel fuels, Chemosphere, 42, 681-690, doi:10.1016/s0045-6535(00)002423, 2001 .

Stevanovic, S., Miljevic, B., Eaglesham, G. K., Bottle, S. E., Ristovski, Z. D., and Fairfull-Smith, K. E.: The use of a nitroxide probe in dmso to capture free radicals in particulate pollution, Eur. J. Organ. Chem., 2012, 5908-5912, doi:10.1002/ejoc.201200903, 2012a.

Stevanovic, S., Ristovski, Z. D., Miljevic, B., Fairfull-Smith, K. E., and Bottle, S. E.: Application of profluorescent nitroxides for measurements of oxidative capacity of combustion generated particles, Chem. Ind. Chem. Eng. Q., 18, 653-659, doi:10.2298/ciceq120113113s, 2012b.

Stevanovic, S., Miljevic, B., Surawski, N. C., Fairfull-Smith, K. E., Bottle, S. E., Brown, R., and Ristovski, Z. D.: Influence of oxygenated organic aerosols (ooas) on the oxidative potential of diesel and biodiesel particulate matter, Environ. Sci. Technol., 47, 7655-7662, doi:10.1021/es4007433, 2013.

Surawski, N. C., Miljevic, B., Ayoko, G. A., Roberts, B. A., Elbagir, S., Fairfull-Smith, K. E., Bottle, S. E., and Ristovski, Z. D.: Physicochemical characterization of particulate emissions from a compression ignition engine employing two injection technologies and three fuels, Environ. Sci. Technol., 45, 5498-5505, doi:10.1021/es200388f, 2011.

Surawski, N. C., Miljevic, B., Bodisco, T. A., Brown, R. J., Ristovski, Z. D., and Ayoko, G. A.: Application of multicriteria decision making methods to compression ignition engine efficiency and gaseous, particulate, and greenhouse gas emissions, Environ. Sci. Technol., 47, 1904-1912, doi:10.1021/es3035208, 2013.

Tinsdale, M., Price, P., and Chen, R.: The impact of biodiesel on particle number, size and mass emissions from a Euro4 diesel vehicle, SAE International Journal of Engines, 3, 597-608, doi:10.4271/2010-01-0796, 2010.

Verma, V., Ning, Z., Cho, A. K., Schauer, J. J., Shafer, M. M., and Sioutas, C.: Redox activity of urban quasi-ultrafine particles from primary and secondary sources, Atmos. Environ., 43, 6360 6368, doi:10.1016/j.atmosenv.2009.09.019, 2009.

Wang, J., Doussin, J. F., Perrier, S., Perraudin, E., Katrib, Y., Pangui, E., and Picquet-Varrault, B.: Design of a new multi-phase experimental simulation chamber for atmospheric photosmog, aerosol and cloud chemistry research, Atmos. Meas. Tech., 4, 2465-2494, doi:10.5194/amt-4-2465-2011, 2011.

Weitkamp, E. A., Sage, A. M., Pierce, J. R., Donahue, N. M., and Robinson, A. L.: Organic aerosol formation from photochemi- 
cal oxidation of diesel exhaust in a smog chamber, Environ. Sci. Technol., 41, 6969-6975, doi:10.1021/es070193r, 2007.

Wickham, H.: Ggplot2: Elegant graphics for data analysis, Springer, 2009.

World Health Organization: Outdoor air pollution a leading environmental cause of cancer deaths, IARC scientific publications, $1-4,2013$.
Xu, Z., Li, X., Guan, C., and Huang, Z.: Characteristics of exhaust diesel particles from different oxygenated fuels, Energy Fuels, 27, 7579-7586, doi:10.1021/ef401946t, 2013.

Zielinska, B.: Atmospheric transformation of diesel emissions, Exp. Toxicol. Pathol., 57, 31-42, doi:10.1016/j.etp.2005.05.006, 2005. 